\title{
First dental visit: Age, reason, and experiences of Saudi children
}

\author{
Nourah Falah Alshahrani ${ }^{1}$, Ayesha Nasser A Alshahrani ${ }^{1}$, Maram Awdah Alahmari ${ }^{1}$, \\ Asrar Mohammed Almanie ${ }^{1}$, Abrar Mohammed Alosbi ${ }^{1}$, Rafi A Togoo ${ }^{1}$
}

Correspondence: Dr. Nourah Falah Alshahrani Email: dr-norah8858@hotmail.com
'Department of Pediatric Dentistry and Orthodontics, College of Dentistry, King Khalid University, Abha, Kingdom of Saudi Arabia

\section{ABSTRACT}

Objective: A study was conducted among parents/guardians of children attending the Outpatient Department of King Khalid University College of Dentistry, Abha, to assess the attitude and knowledge regarding children's first dental visit and related aspects. Materials and Methods: A cross-sectional questionnaire-based study was conducted among a convenient sample of 320 parents/guardians. All the parents/guardians willing to participate in the study and whose children visiting the dentist for the first time were included in the study. Children's behavior was assessed using Frankl's scale. Results: Majority (29\%) of the children visited the dentist for the first time at the age of 3-6 years, while the least percentage (8\%) visited the dentist for the first time at the age of $0-1$ year. A statistically significant difference was found between the responses $(P \leq 0.05)$. Most $(72.67 \%)$ of the children were being accompanied by parents during their first dental visit. About $40.33 \%$ of the parents said that overall experience of the first visit of their children was good. About 39.67\% of the children had positive behavior during their first dental visit. About $37.33 \%$ of the participants said that pain was the main reason for them to get their children to dentist. Conclusion: It was concluded that bulk of the parents were unaware about the appropriate age of their children's first dental visit. Most of the parents brought their children to dentist after their children experienced pain or suffered from dental caries. There is a need to raise awareness among masses regarding the importance of taking oral health care of their children quite seriously at the earliest budding stage of their life.

Key words: Behavior, children, dental caries, dental visit, parents

\section{INTRODUCTION}

Contrary to earlier misconception, when people, undermining importance of the oral health, used to go to dentists for the treatment of their ailing teeth only at the time they could not bear the pain, it is now realized and accepted universally that oral health is an essential part of the general health of any age group be it adults or children. ${ }^{[1]}$ Nevertheless, it has been unfortunate to find that children get victimized to dental caries at the budding stage of their life as early as 12 months of age. ${ }^{[2]}$

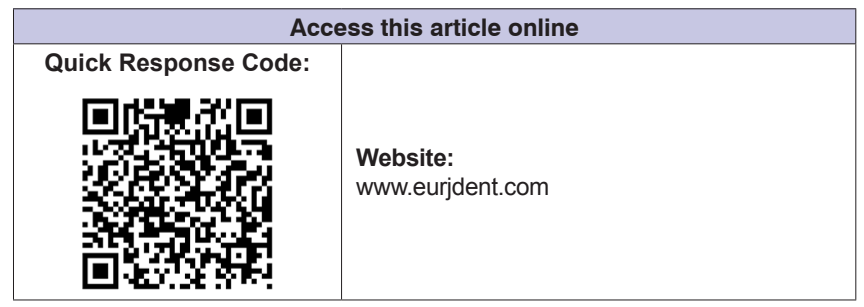

Over and above difficulty in eating, sleeping, altered growth, psychological effect, and also the increased risk of developing dental caries in permanent teeth, pain is the main problem associated with early childhood caries. ${ }^{[3,4]}$ Hence, the prevention of dental caries in children is of greater importance during the early phase of their life so that they are not incapacitated at all to do all the essential activities of their developing life in a healthy manner and to the maximum required degree.

This is an open access journal, and articles are distributed under the terms of the Creative Commons Attribution-NonCommercial-ShareAlike 4.0 License, which allows others to remix, tweak, and build upon the work non-commercially, as long as appropriate credit is given and the new creations are licensed under the identical terms.

For reprints contact: reprints@medknow.com

How to cite this article: Alshahrani NF, A Alshahrani AN, Alahmari MA, Almanie AM, Alosbi AM, Togoo RA. First dental visit: Age, reason, and experiences of Saudi children. Eur J Dent 2018;12:579-84.

DOI: 10.4103/ejd.ejd_426_17 
In several previous studies, oral health status of children has been found associated with attitude and practice of their parents toward providing necessary dental treatment to their wards: children whose parents have positive approach and seriousness in treating them possess better oral health. ${ }^{[5,6]}$ In previous studies, many risk factors such as prolonged breastfeeding, frequent nocturnal bottle feeding, number of family members, oral hygiene practices, diet, timing, and reason for the first visit of a child to the dentist have been documented as prominent causes for the development of caries in early childhood stage. ${ }^{[7]}$

A previous study conducted among parents of Saudi Arabia revealed low level of knowledge among parents regarding the appropriate timing for children's first dental visit. ${ }^{[8]}$

It goes beyond describing that the parents play a major role in imparting education to their children so that they realize the need of being quite aware about the healthy measures and all the related facts. Only in this way, the parents can influence and shape their children's views in a positive way which would ultimately lead to good present and future oral health status of their children. Thus, it is an established fact that the oral and general health of children is significantly affected due to their parents' conception, attitude, and practice toward fully grooming/upbringing of their children to have sound oral health as an essentially integral ingredient of good overall/general health. ${ }^{[9]}$

The factors such as appropriate timing of the first dental visit, knowledge of parents regarding oral health of their children, and past dental experience and behavior of dentist have been considered to be very important as far as optimum delivery/utilization of oral health care is concerned. Furthermore, it is found that a child's behavior during the first dental visit is very importantly decisive since it considerably impacts the future recall visits. ${ }^{[10]}$

Hence, in light of the aforementioned facts and observations, a cross-sectional questionnaire-based study was planned and undertaken in order to adequately assess knowledge and attitude of parents/guardians in Abha, Saudi Arabia, toward the timing of their children's first dental visit and other associated factors.

\section{MATERIALS AND METHODS}

A cross-sectional questionnaire-based study was conducted among parents/guardians of children attending the Outpatient Department of King Khalid University College of dentistry, Abha. Ethical approval was taken from theScientific Research Committee, King Khalid University, Abha, before conducting the study. A convenient sample of 320 participants was included in the study. All the parents (mother or father)/ guardians willing to participate in the study and whose children visiting the dentist for the first time were included in the study. Those parents/guardians whose children suffered from any mental/physical disability were excluded from the study. A self-administered 10-item questionnaire [Appendix 1] was translated into local (Arabic) language for ease in understanding of the participants. The internal validity of the questionnaire was assessed by Cronbach's alpha which was found to be acceptable $(\alpha=0.7)$. The questionnaire included questions related to age at the first dental visit of child, the person accompanying the child to dentist, reasons for the first dental visit, selection of place of treatment, children's behavior during the first visit to dentist, the overall experience and treatment offered at the first visit, and reasons to attend/miss the recall dental visits.

Children's behavior was assessed using Frankl's scale [Appendix 2] ranging from definitely negative to definitely positive. ${ }^{[11]}$ The participants were assured that their responses would not be disclosed so as to maintain the confidentiality. The questionnaires were collected after half an hour from the participants. Out of total 320 respondents, 300 respondents had filled the questionnaire completely. Hence, data received from the duly filled 300 questionnaires were put to statistical analysis.

\section{RESULTS}

Majority $(29 \%)$ of the children visited the dentist for the first time at the age of 3-6 years while the least percentage $(8 \%)$ visited the dentist for the first time at age $0-1$ year. A statistically significant difference was found between the responses $(P \leq 0.05)$. Majority $(72.67 \%)$ of children were being accompanied by parents during their first dental visit. Majority $(40.33 \%)$ of the parents said that overall experience of the first visit of their children was good. About $39.67 \%$ of the children had positive behavior as per Frankl's scale, during their first dental visit. About $53.67 \%$ of the participants said that they might return for the next appointment for their children, while $28.67 \%$ were not sure about their coming for recall visit [Table 1]. About 47.33\% of the participants believed that they would miss the next appointment for their children at dentist because 
they do not require further dental treatment [Table 2]. Majority (37.33\%) of the participants said that pain was the main reason for them to get their children to dentist [Graph 1].

\section{DISCUSSION}

It is very distressing to find that dental caries takes toll of health of a child of an age of $<3$ years which is the budding phase of his life growth. As a matter of fact, owing thereto, preventive measures taken at the early stages hold great significance since it has been observed that incidence of dental caries is high among those who are infected before the age of 3 years. ${ }^{[12,13]}$

In comparison to lower prevalence rates found in most of the developed countries, the prevalence of nursing dental caries was found as to be $27.3 \%$ in a previous study conducted in Riyadh, Saudi Arabia, by Wyne et al. in 2001 $1^{[14,15]}$ causing huge concern for the parents; the various deleterious effects of nursing dental caries range from pain to devastating psychological issues of a child. ${ }^{[16]}$
Over and above other common preventive measures, the important factors facilitative to establishing the oral health of children are proper oral hygiene and balanced diet, awareness about appropriate timing of children's first dental visit, recall visits, behavior of children in dental clinic, and the positive attitude of parents/guardians.

In the current study, as many as $29 \%$ of the children are reported to have visited the dentist for the first time at the age of 3-6 years, while the least percentage of $8 \%$ visited the dentist for the first time at the age of $0-1$ year. This finding corroborates with various previous studies conducted in Saudi Arabia, wherein the parents/guardians exposed their children to dentist at 3-6 years of age. ${ }^{[17,18]}$ The underlying reason is their misconception, whereby they do not require to take their children to dentists/ pedodontists unless any problem arises, especially before the age of 1 year.

It is really astonishing to know that in various previous researches ${ }^{[19,20]}$ carried out in other parts of the world, the age of 7-11 years and 6-12 years was being reported

\begin{tabular}{|c|c|c|c|c|c|}
\hline \multicolumn{2}{|c|}{$\begin{array}{c}\text { Age of the child at the time of first } \\
\text { visit }\end{array}$} & \multicolumn{2}{|c|}{$\begin{array}{l}\text { Person accompanying the } \\
\text { child at the time of first visit }\end{array}$} & \multicolumn{2}{|c|}{ Overall experience of first dental visit } \\
\hline Age & $n(\%)$ & Person & $n(\%)$ & Experience & $n(\%)$ \\
\hline $0-1$ year & $24(8.00)$ & Parent & $218(72.67)$ & Very good & $102(34.00)$ \\
\hline $1+-3$ years & $51(17.00)$ & Sibling & $26(8.67)$ & Good & $121(40.33)$ \\
\hline $3+-6$ years & $87(29.00)$ & Grand parent & $27(9.00)$ & Satisfactory & $43(14.33)$ \\
\hline $6+-9$ years & $86(28.67)$ & Guardian & $29(9.67)$ & Bad & $24(8.00)$ \\
\hline$>9$ years & $52(17.33)$ & Alone & $0(0.00)$ & Very bad & $10(3.33)$ \\
\hline$\chi^{2}(\mathrm{df})$ & $47.433(4)^{*}$ & $\chi^{2}(\mathrm{df})$ & $529.500(4)^{*}$ & $\chi^{2}(\mathrm{df})$ & $159.500(4)^{*}$ \\
\hline \multicolumn{2}{|c|}{$\begin{array}{l}\text { Child's behavior during first } \\
\text { dental visit }\end{array}$} & \multicolumn{2}{|c|}{$\begin{array}{l}\text { Are you likely to return for next } \\
\text { appointment? }\end{array}$} & \multicolumn{2}{|c|}{$\begin{array}{l}\text { What treatment was provided at the first time of } \\
\text { the visit? }\end{array}$} \\
\hline Definitely positive & $96(32.00)$ & Definitely yes & $34(11.33)$ & Problem for visit was treated & $121(40.33)$ \\
\hline Positive & 119 (39.67) & Probably no & $86(28.67)$ & Only oral examination/X-ray done & $74(24.67)$ \\
\hline Negative & $54(18.00)$ & Definitely no & $19(6.33)$ & Only medication prescribed & $48(16.00)$ \\
\hline Definitely negative & $31(10.33)$ & Probably yes & $161(53.67)$ & Only advice provided & $57(19.00)$ \\
\hline$\chi^{2}(\mathrm{df})$ & $63.387(3)^{*}$ & $\chi^{2}(\mathrm{df})$ & $164.453(3)^{*}$ & $\chi^{2}(\mathrm{df})$ & $42.267(3)^{*}$ \\
\hline
\end{tabular}

\begin{tabular}{|c|c|c|c|c|c|}
\hline \multicolumn{2}{|c|}{$\begin{array}{c}\text { Reason for selecting the place of } \\
\text { treatment }\end{array}$} & \multicolumn{2}{|c|}{$\begin{array}{l}\text { What would be the main reason for you to } \\
\text { keep your next appointment? }\end{array}$} & \multicolumn{2}{|c|}{$\begin{array}{l}\text { What would be the reason for you to miss } \\
\text { your next appointment? }\end{array}$} \\
\hline Reason & $n(\%)$ & Next appointment kept reason & $n(\%)$ & Next appointment miss reason & $n(\%)$ \\
\hline Quality of treatment & $82(27.33)$ & $\begin{array}{l}\text { The treatment provided } \\
\text { relieved my problem }\end{array}$ & $80(26.67)$ & Treatment did not provided relieve & $49(16.33)$ \\
\hline Advice from friends/relatives & $70(23.33)$ & Behavior of dental professionals & $49(16.33)$ & Dentist behavior of was not good & $46(15.33)$ \\
\hline Previous personal experience & $99(33.00)$ & Importance of dental treatment & $74(24.67)$ & Further treatment not required & $142(47.33)$ \\
\hline Distance from home & $35(11.67)$ & For completing my treatment & $76(25.33)$ & Any other & $63(21.00)$ \\
\hline Other & $14(4.67)$ & Any other & $21(7.00)$ & & \\
\hline$\chi^{2}(\mathrm{df})$ & $80.767(4)^{*}$ & $\chi^{2}(\mathrm{df})$ & $41.567(4)^{\star}$ & $\chi^{2}(\mathrm{df})$ & $82.000(3)^{*}$ \\
\hline
\end{tabular}




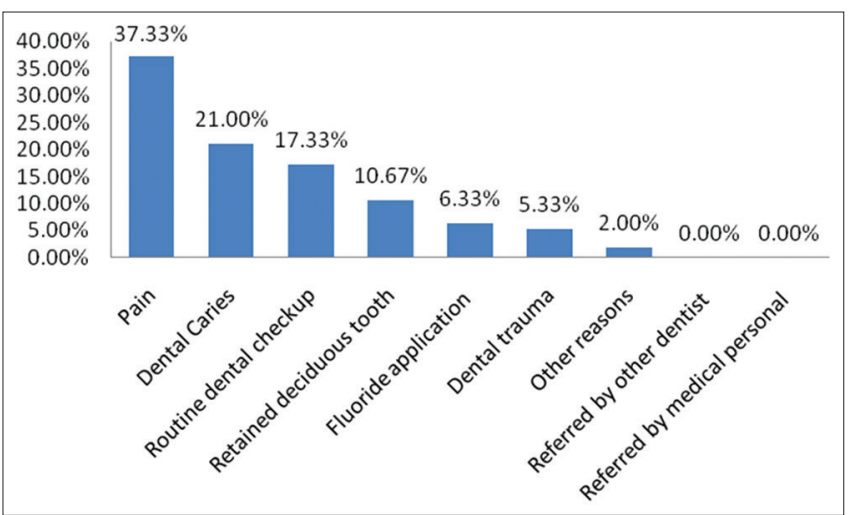

Graph 1: Frequency distribution of participants based on the reasons for the first dental visit of their children

as the age for the first dental visit for their children. In a yet another study conducted in Bulgaria, the researchers noted that the study participants did not take their children to dentist earlier of the age of 1 year and they only visited the dentist in case their children suffered from dental caries or its complication. ${ }^{[21]}$ Such findings are quite indicative of the unawareness among parents regarding the appropriate age of their children for visiting the dentist for the first time. The recommended age by the American Academy of Pediatrics $^{[22]}$ is the period between 6 months of age and the eruption of the first tooth.

The significance of early dental visits has been justified on the basis of various reasons such as prevention of early childhood caries, detection of incipient dental caries lesion at its earliest stages so as to prevent further progression of the same, and evaluation of dental and craniofacial growth. Moreover, other factors include counseling of parents regarding appropriate and effective oral hygiene habits, healthy dietary habits, use of fluoride, balanced diet, and motivating parents toward timely preventive measures for attaining good oral health among their children. ${ }^{[22]}$

The findings of the present study show that majority of the children $(72.67 \%)$ were accompanied by parents during their first dental visit. It is evident that parents, especially mothers being overprotective, prefer to be with their children while undergoing treatment at dentist. Parents' role and attitude have been documented in previous studies as having an essential impact on children's behavior as well as their apprehension toward dental treatment which eventually lays considerable impact on oral health of children. ${ }^{[23,24]}$

About $39.67 \%$ of the children were found to have positive behavior during their first dental visit. This finding was similar to previous study in Riyadh, Saudi Arabia, wherein majority of the participants are reported to have behaved positively during their first dental visit. ${ }^{[25]}$ The reasons thereof might be the fact that they were provided with conducive environment while undergoing treatment. Moreover, majority of the children aged 3-6 years were found more cooperative.

To measure the child's behavior, Frankl's scale was being used which has been reported to be the most reliable scale to assess the behavior of children in clinics. ${ }^{[26]}$ This scale assists in predicting the future appointments of pediatric patients. ${ }^{[10]}$ Results of the present study show that owing to the positive behavior of their children while undergoing dental treatment, majority of the parents $(40.33 \%)$ felt good as far as their overall experience of their children's first dental visit was concerned. As a good percentage of children (26.67\%) in the present study are reported having been relieved of the problem for which they were brought to dentist, so their parents were satisfied with overall experience of the first dental visit of their children.

When, as recorded in the present study, the parents were inquired about the reasons for them to get their children to dentist for the first time, bulk of them assigned the reason to the dental pain $(37.33 \%)$ followed by dental caries (21\%). These results were in accordance with previous studies, wherein the main reasons of children's first dental visit were pain and dental caries. ${ }^{[19,27]}$

Such findings confirm the lack of awareness among masses about visiting dentists for regular dental checkups of their children so as to prevent the occurrence of ailments such as dental caries and its associated complications.

Around $47.33 \%$ of the participants are reported to believe that they would not turn up for the next appointment for their children at dentist, as according to them, it was not needed. This finding calls attention of all the dental professionals, pediatric dentists, public health dentists, and other health workers to work efficiently and collaboratively so as to create awareness among the populace regarding regular dental examination and importance of recall visits. The dental professionals, during in-office hours while undertaking the dental treatment of their children, need to adequately educate the parents/guardians. Furthermore, the oral health education should be 
emphasized upon at community and school levels during various health awareness programs.

\section{CONCLUSION}

It is fairly concluded that bulk of the parents were unaware about the appropriate age of their children's first dental visit. Most of the parents brought their children to dentist after their children experienced pain or suffered from dental caries. There is ample need to raise awareness among masses regarding the importance of taking oral health care of their children quite seriously at the earliest budding stage of their life.

\section{Financial support and sponsorship}

Nil.

\section{Conflicts of interest}

There are no conflicts of interest.

\section{REFERENCES}

1. Al-Zahrani AM, Al-Mushayt AS, Otaibi MF, Wyne AH. Knowledge and attitude of Saudi mothers towards their preschool children's oral health. Pak J Med Sci 2014;30:720-4.

2. Prakash P, Subramaniam P, Durgesh BH, Konde S. Prevalence of early childhood caries and associated risk factors in preschool children of urban Bangalore, India: A cross-sectional study. Eur J Dent 2012;6:141-52.

3. Filstrup SL, Briskie D, da Fonseca M, Lawrence L, Wandera A, Inglehart MR, et al. Early childhood caries and quality of life: Child and parent perspectives. Pediatr Dent 2003;25:431-40.

4. Almeida AG, Roseman MM, Sheff M, Huntington N, Hughes CV. Future caries susceptibility in children with early childhood caries following treatment under general anesthesia. Pediatr Dent 2000;22:302-6.

5. Friedman LA, Mackler IG, Hoggard GJ, French CI. A comparison of perceived and actual dental needs of a select group of children in Texas. Community Dent Oral Epidemiol 1976;4:89-93.

6. Eijkman MA, Howvink B, De With C. Some aspects of patient education by dentists of mothers with young children. Neth Dent J 1978;85:6-33.

7. Wyne AH. Early childhood caries. A review. Indian J Dent Res 1996;7:7-15.
8. Al-Shalan TA, Al-Mousa BA, Al-Khamis AM. Saudi parents' attitude toward children's first dental visit in college of dentistry, king Saud university: A survey. Saudi Med J 23:1110-4.

9. Szatko F, Wierzbicka M, Dybizbanska E, Struzycka I, Iwanicka-Frankowska E. Oral health of polish three-year-olds and mothers' oral health-related knowledge. Community Dent Health 2004;21:175-80

10. Klinberg G. Dental anxiety and behaviour management problems in paediatric dentistry - A review of background factors and diagnostics. Eur Arch Paediatr Dent 2008;9 Suppl 1:11-5.

11. Clinical Affairs Committee-Behavior Management Subcommittee, American Academy of Pediatric Dentistry. Guideline on Behavior Guidance for the Pediatric Dental Patient. Pediatr Dent 2015;37:57-70.

12. Febres C, Echeverri EA, Keene HJ. Parental awareness, habits, and social factors and their relationship to baby bottle tooth decay. Pediatr Dent 1997;19:22-7.

13. Kinirons M, McCabe M. Familial and maternal factors affecting the dental health and dental attendance of preschool children. Community Dent Health 1995;12:226-9.

14. Wyne A, Darwish S, Adenubi J, Battata S, Khan N. The prevalence and pattern of nursing caries in Saudi preschool children. Int J Paediatr Dent 2001;11:361-4.

15. Ripa LW. Nursing caries: A comprehensive review. Pediatr Dent 1988;10:268-82

16. Acs G, Lodolini G, Kaminsky S, Cisneros GJ. Effect of nursing caries on body weight in a pediatric population. Pediatr Dent 1992;14:302-5.

17. Al-Shalan TA. Factors affecting Saudi parents' perception of their children's first dental visit. J Contemp Dent Pract 2003;4:54-66.

18. Al-Shalan TA, Al-Musa BA, Al-Khamis AM. Parents' attitude towards children's first dental visit in the college of dentistry, Riyadh, Saudi Arabia. Saudi Med J 2002;23:1110-4.

19. Ghimire N, Kayastha B, Nepal P. The first dental visit. J Chitwan Med Coll 2013;3:30-3.

20. Meera R, Muthu MS, Phanibabu M, Ratnaprabhu V. First dental visit of a child. J Indian Soc Pedod Prev Dent 2008;26:68-71.

21. Mileva SP, Kondeva VK. Age at and reasons for the first dental visit. Folia Med (Plovdiv) 2010;52:56-61.

22. Geoffrey RS, Cynthia Baker, Graham A Barden $3^{\text {rd }}$, Brown OW, Hardin A, Lessin HR, et al. 2014 recommendations for pediatric preventive health care. Pediatrics 2014;133:568-70.

23. Sakai VT, Oliveria TM, Silva TC, Moretti AB, Geller-Palti D, Biella VA, et al. Knowledge and attitude of parent or caretakers regarding transmissibility of caries disease. JAppl Oral Sci 2008;261:32-44.

24. Saied-Moallemi Z, Virtanen JI, Ghofranipour F, Murtomaa H. Influence of mothers' oral health knowledge and attitudes on their children's dental health. Eur Arch Paediatr Dent 2008;9:79-83.

25. Murshid EZ. Children's ages and reasons for receiving their first dental visit in a Saudi community. Saudi Dent J 2016;28:142-7.

26. Wright GZ, Stigers JI. Nonpharmacologic management of children's behaviors. In: Dean JA, Avery DR, Mc-Donald RE, editors. McDonald and Avery's Dentistry for the Child and Adolescent. $9^{\text {th }}$ ed. Maryland Heights, Mo: Mosby-Elsevier; 2011. p. 27-40.

27. Soxman JA. The first dental visit. Gen Dent 2002;50:148-55. 


\section{APPENDICES}

\section{Appendix 1: Questionnaire}

Q1. Age of the child at the time of first visit
a. $0-1$ year
b. $1+$ to 3 years
c. $3+$ to 6 years
d. $6+$ to 9 years
e. Above 9 years.

Q2. Person accompanying the child at the time of first visit
a. Parents
b. Sibling
c. Grand Parent
d. Guardian
e. Alone.

Q3. Reason for the first dental visit
a. Pain
b. Dental caries
c. Routine dental check up
d. Retained deciduous tooth
e. Fluoride application
f. Referred by dentist
g. Referred by medical personnel
h. Trauma
i. Any Other

Q4. Reason for selecting the place of treatment
a. Quality of treatment
b. Advice from Friends/relatives
c. Previous personal experience
d. Distance from home
e. Any other.

Q5. What treatment was provided at the first time of the visit
a. Problem for visit was treated
b. Only oral examination/x-ray done
c. Only medication prescribed
d. Only advice given.

Q6. Child's behavior during first dental visit
a. Definitely positive
b. Positive
c. Negative
d. Definitely negative.

Q7. Are you likely to return for next appointment?
a. Definitely yes
b. Probably no
c. Definitely no
d. Probably yes.

Q8. Overall experience of first dental visit
a. Very good
b. Good
c. Satisfactory
d. Bad
e. Very Bad.

Q9. What would be the main reason for you to keep your next appointment?
a. The treatment provided relieved my problem
b. Behavior of dental professionals
c. Importance of dental treatment
d. For completing my treatment
e. Any other.

Q10. What would be the reason for you to miss your next appointment?

a. The treatment provided did not relieve my problem

b. Behavior of dentist was not good

c. Further dental treatment not required

d. Any other.

\section{Appendix 2: Frankl's Scale}

1. -- Definitely negative. Refusal of treatment, forceful crying, fearfulness, or any other overt evidence of extreme negativism

2. - Negative. Reluctance to accept treatment, uncooperative, some evidence of negative attitude but not pronounced (sullen, withdrawn)

3. ++ Positive. Acceptance of treatment; cautious behavior at times; willingness to comply with the dentist, at times with reservation, but patient follows the dentist's directions cooperatively 4 . + Definitely positive. Good rapport with the dentist, interest in the dental procedures, laughter and enjoyment. 